\title{
LA RELACIÓN ENTRE PECADO ORIGINAL Y DOMINIO POLÍTICO EN UN TRATADO DE JOHN WYCLIF
}

THE RELATIONSHIP BETWEEN ORIGINAL SIN AND POLITICAL DOMINION IN A TRACTATE OF JOHN WYCLIF

Cecilia Devia *

deviacecilia@gmail.com

RESUMEN: A efectos de estudiar la relación entre pecado original y dominio político en el Tractatus de statu innocencie (1376) de John Wyclif, se comenzará por presentar los dos relatos bíblicos de la creación, con sus similitudes y diferencias. Se continuará comentando el célebre contrafáctico sobre la primera pareja humana: ¿qué habría pasado si Adán y Eva no hubieran pecado?, empleado por los pensadores medievales para desarrollar todo tipo de preguntas y elaboraciones sobre la situación del momento en el que escribían sus obras. Se abordarán asimismo los diferentes tipos de dominio que se pueden identificar en el Génesis. Finalmente se analizará el tratado en cuestión, particularmente en cuanto a la relación entre pecado original, dominio, propiedad y uso.

Palabras Clave: Pecado original, Dominio político, Wyclif.

ABSTRACT: In order to study the relationship between original sin and political dominion in John Wyclif's Tractatus de statu innocencie (1376), we will begin by presenting the two biblical accounts of creation, with their similarities and differences. We will continue commenting on the famous counterfactual about the first human couple: what would have happened if Adam and Eve had not sinned ?, used by medieval thinkers to develop all kinds of questions and elaborations on the situation of the moment in which they wrote their works. The different types of dominion that can be identified in Genesis will also be addressed. Finally, the tractate in question will be analyzed, particularly as regards the relationship between original sin, dominion, property and use.

KEYWORDS: Original Sin, Political Dominion, Wyclif.

\section{Introducción}

El estudio de las relaciones entre pecado original y dominio político emprendido por el pensamiento medieval constituye un tema clave en la filosofía política. De ahí la proliferación de todo tipo de escritos sobre ese tema y otros conexos durante el período en cuestión, y el interés que todavía despiertan en la actualidad.

La elección de la figura de John Wyclif (1328-1384) como referencia principal, y de su Tractatus de statu innocencie ${ }^{1}$ en particular, obedece a varias razones. Por un lado, es un autor sobre el que existe una amplísima bibliografía, pero que ha sido poco trabajado en nuestro medio, en especial en relación a nuestro tema de indagación. Por otra parte, su visión sobre el mismo es compleja y meditada, a la vez que realiza una crítica que apunta a la reforma de lo existente. Todas estas cualidades lo convierten en un objeto adecuado para una

\footnotetext{
* Doctora en Historia Medieval (Universidad de Buenos Aires). Posdoctorado en Ciencias Sociales (Universidad de Buenos Aires). Investigadora del Instituto de Historia Antigua y Medieval "Prof. José L. Romero", FFyL, UBA. ${ }^{1}$ A partir de ahora lo citaremos como el TDSI.
} 
investigación sobre el vínculo entre pecado original y dominio, enfocada especialmente desde la filosofía política².

En cuanto a la fuente en sí, el tratado elegido - que forma parte de la extensa obra en latín de Wyclif - es relativamente breve, ha sido poco estudiado y trata específicamente lo que pretendemos investigar. Por otra parte, Elemér Boreczky afirma que las obras latinas de Wyclif han sido muy poco abordadas por los investigadores en general, con lo que juzgamos que el presente podría ser un aporte de interés para los estudios sobre el pensador inglés (BORECZKY, 2008, p. 6).

\section{Los dos relatos bíblicos de la creación}

El primer relato de la creación comienza al mismo tiempo que el Génesis y finaliza en Génesis 2:3. Narra cómo Dios creó al mundo en seis días, coronando su obra con la creación de Adán - y con él, de la humanidad - a su imagen y semejanza. En Génesis 2:4 comienza el segundo relato de la creación, donde cuenta cómo el Señor hizo un hombre con polvo de la tierra, para crear después a todos los animales. Al no encontrar entre ellos ningún compañero adecuado para Adán, lo hizo caer en un sueño profundo, sacó a Eva de su costado y se la presentó como su esposa (PAGELS, 1998, p. 16).

Muchos estudiosos de la Biblia acuerdan en que los dos relatos de la creación, separados en un comienzo, fueron luego unidos para configurar los tres primeros capítulos del Génesis. En cuanto a la datación de ambos, el que se encuentra ahora ubicado en primer lugar dataría de alrededor del año 400 a.C., mientras que el segundo sería el más antiguo de los dos, fechándose entre los años 1000 y 900 a.C. (PAGELS, 1998, p. 16).

Robert Burt indica que en el primer capítulo del Génesis los actos creativos de Dios se mueven progresivamente: el primer día divide la luz de las tinieblas; el segundo, el cielo de la tierra; el tercero, separa la tierra firme de los mares y planta semillas de pastos, árboles y frutas; el cuarto día crea el sol, la luna y las estrellas; el quinto día, crea los animales; el sexto día, crea a los humanos, macho y hembra juntos, a imagen de él mismo. Según el narrador

\footnotetext{
${ }^{2}$ Esta presentación forma parte de una investigación más amplia emprendida en una tesis en elaboración en el marco de la Maestría en Filosofía Política (Facultad de Filosofía y Letras-Universidad de Buenos Aires), titulada Pecado original y dominio político en el Tractatus de statu innocencie de John Wyclif, bajo la dirección de la Dra. Carolina Julieta Fernández).
} 
bíblico, cuando el quinto día observa su creación, concluye que era buena, mientras que, luego de crear a la humanidad, evalúa su esfuerzo como muy bueno (BURT, 2012, p. 2).

En el séptimo día, Dios descansó. Y es a partir de aquí donde la narrativa del capítulo dos, en palabras de Burt, toma un extraño giro. Hace volver al lector a la situación imperante en el tercer día de la creación, después de que Dios hubiera hecho la tierra y los cielos, pero antes de que aparecieran plantas, animales o humanos. Había solo polvo estéril en el universo. De este polvo, Dios formó al hombre y le insufló vida en sus fosas nasales. Este hombre (adam en hebreo) fue inicialmente creado solo en la tierra, a diferencia del relato del primer capítulo, donde los animales preceden a la humanidad, y macho y hembra son creados al mismo tiempo (BURT, 2012, p. 2).

Luego de la creación de Adán, Dios planta un jardín en el Edén. Pero mientras que en el primer relato toda la tierra abundaba en plantas, árboles y frutos para el consumo de animales y humanos, el jardín del segundo relato es un lugar amurallado rodeado de tierra estéril. Dios ubica a Adán solo en el jardín, e inmediatamente dicta su primer mandamiento negativo, indicándole a Adán que puede comer el fruto de cualquier árbol de ese jardín, excepto el del árbol del conocimiento del bien y del mal. A lo que agrega que, si lo hace, estará condenado a morir (BURT, 2012, p. 2-3).

Burt subraya la presencia de la que califica como una sorprendente admisión en el segundo capítulo del Génesis. Luego de su enorme esfuerzo al crear a todos los animales para hacerle a Adán una ayuda adecuada, queda claro que Dios no tuvo éxito en esta tarea. De ahí que elige otro camino, y crea a Eva a partir del propio Adán. Así como en el primer relato de la creación Dios se muestra orgulloso de su obra, observando que estaba buena e, incluso, muy buena, en el segundo se revelaría una debilidad de Dios, la que es inmediatamente subsanada con la creación de Eva.

Burt observa que, al ver a Eva, Adán exclama: “Esta vez sí que es hueso de mis huesos y carne de mi carne" (Gén. 2:23). ${ }^{3}$ Estas son sus primeras palabras registradas en la Biblia. En la reacción de Adán ante la creación de Eva se pueden ver los primeros indicios de la pretensión humana de evaluar a Dios. Burt refuerza esta observación al indicar que una convención literaria rige todo el texto de la Biblia hebrea: las primeras palabras dichas por cualquier actor revelan su carácter esencial (BURT, 2012, p. 5).

\footnotetext{
${ }^{3}$ Los pasajes bíblicos citados en este artículo son tomados de la que se conoce como Biblia de Jerusalén. 
Por otra parte, Burt sostiene que la presencia de significados contradictorios es un aspecto esencial de la estrategia narrativa de la Biblia, que se refleja en su tema subyacente de elogiar la obediencia incondicional a la voluntad de Dios, al mismo tiempo que el texto plantea reiteradas preguntas sobre la legitimidad de la autoridad de Dios para demandar obediencia (BURT, 2012, p. XII).

\section{Pecado original y dominio político en el Génesis}

Ya ingresando en el tema del pecado original y la subsecuente caída de la primera pareja humana, que arrastra a la humanidad toda, Alistair Minnis afirma que la impotencia de la humanidad no fue un rasgo de su creación, sino un castigo por su transgresión (MINNIS, 2016, p. 14). Haremos una breve mención aquí del célebre contrafáctico que permitió principalmente a lo largo de la Edad Media - interpretaciones de carácter que podríamos denominar filosófico, muy variadas: ¿qué habría pasado si Adán y Eva no hubieran pecado?, o, formulado en términos positivos: ¿qué habría pasado si los padres del género humano hubieran permanecido en el estado de inocencia original? A partir de este contrafáctico se derivan cantidad de preguntas, respuestas e interpretaciones que apuntan al estudio de la vida política de los seres humanos tal como se desarrollaba en el momento en que los distintos pensadores las escribían. En relación a la creencia en el poder o dominio del hombre sobre la vida animal y vegetal en la Edad Media, Minnis sostiene que parece provenir directamente de la palabra divina tal como se registra en el primer capítulo del Génesis: "Hagamos al ser humano a nuestra imagen, como semejanza nuestra, y manden en los peces del mar y en las aves de los cielos, y en las bestias y en todas las alimañas terrestres, y en todas las sierpes que serpean por la tierra" (Gén. 1:26). Y luego se ordena a la primera pareja humana: "Sed fecundos y multiplicaos y henchid la tierra y sometedla; mandad en los peces del mar y en las aves de los cielos y en todo animal que serpea sobre la tierra" (Gén. 1:28). En el versículo intermedio, se afirma que Dios creó "al ser humano a imagen suya [...], macho y hembra..." (Gén. 1:27), mientras que en el segundo relato parece bastante claro que a Adán se le dio dominio sobre los animales antes de que Eva fuera creada (Gén. 2:19-22). Es aquí donde aparece la estrategia que empleó Dios para afirmar el dominio de Adán sobre los animales, antes de que fuera creada Eva: "Y Yahveh Dios formó del suelo todos los animales del campo y todas las aves del cielo y los llevó ante el hombre para ver cómo los llamaba, y para que cada ser viviente tuviese el nombre que el hombre le diera" (Gén. 2:19); “El hombre puso nombres 
a todos los ganados, a las aves del cielo y a todos los animales del campo, mas para el hombre no encontró una ayuda adecuada" (Gén. 2:20) (MINNIS, 2016, p. 144). Y al nominarlos, el primer hombre los domina.

En los relatos de la creación contenidos en el Génesis se puede intentar identificar diferentes tipos de dominio: el dominio del ser humano sobre el resto de la creación, el del hombre sobre la mujer, el del hombre sobre el hombre. Nuestro foco estará puesto en esta última manifestación del dominio. Aunque todas las formas enunciadas tienen carácter político, consideramos que el dominio del hombre sobre el hombre sería el dominio político por excelencia, de ahí que nuestro interés principal esté puesto en él.

\section{Wyclif y el Tractatus de statu innocencie}

John Wyclif es una figura particularmente polifacética, tanto por lo que efectivamente pueda haber sido como por todo lo que inspiró, en vida y después de su muerte. Wyclif ha sido estudiado como el precursor de la Reforma, el traductor de la Biblia al inglés, el instigador de la revuelta campesina inglesa de 1381, el cerebro y el alma detrás de la herejía lolarda y de la husita, el hereje cuyas obras fueron condenadas y quemadas y su cadáver exhumado y execrado por orden de la Iglesia, el político al servicio de Juan de Gante y de la Corona inglesa, el lógico implacable, el metafísico impulsor de un ultra-realismo, el teólogo más profundo y sutil, y aun más. ${ }^{4}$

El Tractatus de statu innocencie (1376) es una obra relativamente breve dentro de la producción de Wyclif. Minnis considera que ha recibido poca atención, pero que su argumento tiene integridad y consistencia, si bien - a su juicio - su autor procede de manera un tanto ambigua y repetitiva (MINNIS, 2012, p. 61). Gianluca Briguglia lo define como un tratado breve pero muy complejo, donde el modelo de humanidad es el de Adán antes de la caída: el hombre natural perfecto (BRIGUGLIA, 2017, p. 28-29).

Por su parte, Boreczky agrega que contiene algunos de los principios fundamentales elaborados por el pensador inglés, ya que allí trata de reconstruir el dominio natural y la vida en el estado de inocencia (BORECZKY, 2008, p. 119). Lo considera un testimonio de la lucha de Wyclif para integrar la filosofía natural y la ética aristotélicas, la cosmovisión dionisiana y sus

\footnotetext{
${ }^{4}$ Es imposible intentar resumir aquí la amplísima bibliografía sobre John Wyclif. En el análisis emprendido en este artículo solo se trabajará con una brevísima selección de obras relacionadas específicamente con el tema en cuestión.
} 
propias ideas revolucionarias sobre la naturaleza de la Iglesia y los servicios debidos a Dios (BORECZKY, 2008, p. 120).

En un artículo donde analiza minuciosamente el tratado en cuestión, Luigi Campi indica que allí Wyclif describe los rasgos del hombre en el estado edénico, conectándolos con algunos temas destacados de la escolástica y del pensamiento medieval en general, concernientes a la naturaleza, el dominio, la gracia y el libre albedrío. Este tratado puede ser considerado como un laboratorio en el cual Wyclif probó los conceptos sobre los que iba a trabajar más adelante (CAMPI, 2007, p. 89).

En líneas generales, Minnis indica que los pensadores medievales encontraron en el estado de inocencia un contexto habilitante - quizá incluso un espacio transformador - para el pensamiento, en el que la situación presente de la humanidad podía ser dejada de lado y los temas analizados sin las restricciones impuestas a la investigación por las condiciones y demandas de la vida después de la caída. Aquí la especulación podía ser perseguida sin preocupaciones de consecuencia práctica o relevancia contemporánea. Cuando los teólogos medievales debatían sobre la naturaleza del sexo, la horticultura, la comida, el ritual o sobre cualquier forma de actividad humana antes de la caída, estaban hablando de lo que podría haber sido, más bien que lo que realmente había sido en un momento histórico real (MINNIS, 2012, p. 59-60). De cualquier manera, añadimos que es necesario tener presente la insistencia de Agustín, principalmente en De Genesi ad litteram, en considerar lo que se relata en el Génesis como sucesos históricos.

No es esta la ocasión de seguir el TDSI paso a paso, sino que nos ceñiremos al tema del presente artículo. Ya al comienzo del tratado Wyclif da una definición del estado de inocencia: es el estado de una naturaleza racional libre de pecado, tal como el de Adán en el Paraíso, el de Cristo y - parcialmente - el de algunos santos. Unas líneas más abajo agregará el estado de los santos in patria, ${ }^{5}$ o sea, en la bienaventuranza.

Más adelante ofrecerá una definición del pecado original, indicando que no es el estímulo del pecado o la propensión al mismo, porque permanece despúes del bautismo; tampoco lo es el deleite excesivo. El pecado original es la privación originaria de justicia, cuando el hijo de Adán falta a la justicia del Reino de modo continuo desde el origen. De este

\footnotetext{
${ }^{5}$ Supponamus ergo in primis quod status innocencie sit status nature racionalis immunis simpliciter a peccato, cuiusmodi fuit status primi parentis in quo vixerat ante lapsum, status quoque Christi ex integro ac status parcialis aliorum sanctorum, si qui per tempus vixerint immunes simpliciter a peccato, et status sanctorum in patria (TDSI, C. 1, p. 475).
} 
pecado se siguen los males referidos anteriormente y otros similares. ${ }^{6}$ El pecado, entonces, se definiría formalmente como un apartamiento del orden justo que se debe a Dios, y no como un acto puntual de los sentidos. Pero es importante tener presente que, para Wyclif, si bien después del bautismo se remueve el pecado original, queda una propensión a pecar que el sacramento no borra.

A lo largo de todo el tratado Wyclif desarrolla las argumentaciones propias del método escolástico. Alude a ello cuando indica que para averiguar que habría pasado si la primera pareja humana no hubiera pecado va a emplear las Escrituras, los dichos de los santos y la razón probable ${ }^{7}$. Así, se suceden citas o referencias bíblicas, a los Padres de la Iglesia particularmente a Agustín - , al Filósofo por excelencia - Aristóteles - y, en menor medida, a pensadores más cercanos en el tiempo, como Roberto Grosseteste.

Wyclif sostiene que toda pena es a causa de un mal y que Dios no castiga sin motivo. Si alguien es castigado, se deduce que es porque pecó. ${ }^{8}$ Si la humanidad no hubiera pecado, no habría podido ser castigada ${ }^{9}$. El pecado también es causa de la muerte. Si el género humano hubiera continuado sin pecado, también habría permanecido sin castigo. De esto se sigue que habría sido también inmortal. ${ }^{10}$

\footnotetext{
${ }^{6}$... nec est putandum quod fomes peccati vel pronitas ad peccandum sit originale peccatum formaliter, cum maneat post baptismum. Nec excessiva delectacio cum sit actualis et personalis sed originalis privacio iusticie est originale peccatum, quando scilicet filius Ade continue a sua origine deficit a iure regni, ad quod peccatum predicta mala cum sibi similibus consecuntur; et patet quod utrobique sensus et membra hominis attenta proporcione agunt secundum sui ultimum. Et patet materia respondendi argumentis multiplicatis in ista materia (TDSI, C. 5, p. 504-505).

${ }^{7}$ Videndum est igitur quid convenisset humano statui, si totum genus hominis perpetuo statum innocencie observasset, pro cuius indagine utendum est testimonio scripture, dictis sanctorum et probabili racione (TDSI, C. 1, p. 475).

${ }^{8}$ Cum enim omnis pena si est a Deo iuste infligitur, patet quod si non esset peccatum non superesset causa quare Deus penam infligeret: sed et hoc diffuse prosecutus sum in materia de adnichilacione (TDSI, C. 1, p. 476).

${ }^{9}$ Primo videtur sequi quod, si totum genus humanum perpetuo non peccasset, fuisset secundum se totum impune simpliciter (TDSI, C. 1, p. 475).

${ }^{10}$ Supposito itaque tanquam theoreumate ad dicenda quod, si totum genus humanum continue mansisset sine peccato, mansisset eciam sine pena, videtur correlarie sequi primo quod genus hominum fuisset eciam immortale, non solum habendo disposicionem secundum quam poterat nunquam mori, sed qua servata non esset compossibile ipsum mori (TDSI, C. 2, p. 480).
} 
El hombre fue creado autosuficiente, para servir a Dios y dominar naturalmente a todas las naturalezas corpóreas. ${ }^{11}$ Ese argumento filosófico, sostiene Wyclif, se enseña en la historia relatada en Génesis II, ${ }^{12}$ a la que ya hemos hecho referencia.

Más adelante el autor entra de lleno en el otro asunto que nos convoca, cuando presenta - siguiendo la típica argumentación escolástica - la duda respecto a si en el estado de inocencia las cosas temporales fueron comunes a todos. ${ }^{13}$ Para tratar este tema, asegura, se requiere un conocimiento del dominio, la propiedad y la comunidad de bienes. ${ }^{14} \mathrm{La}$ conclusión a la que llega es que todas las cosas fueron comunes a todos en el estado de inocencia. ${ }^{15}$

Wyclif vuelve a citar aquí al Génesis - esta vez l, 26 -, donde se trata la creación del hombre a semejanza de Dios y el otorgamiento del dominio sobre toda la creación. ${ }^{16}$ A partir de esto sostiene su teoría sobre el dominio natural y el uso: Dios da al inocente el dominio natural y lo autoriza a usar cualquier cosa necesaria para el hombre y para que este sirva a Dios. ${ }^{17}$ La propiedad o apropiación civil solo se introduce para refrenar a los viciosos, a los abusadores, una vez que el hombre ha pecado. Es decir, como remedio para la vida humana en estado postlapsario. La propiedad civil repugna al estado de inocencia. ${ }^{18}$

El estado de inocencia permite el uso y el disfrute de un bien, lo que distingue el uso del abuso. El inocente usa cualquier parte del mundo, en la forma de un placer ordenado y en

\footnotetext{
${ }^{11}$ Ideo catholici clarius tollunt instanciam antiquorum, concedentes quod homo in ordinatione primaria creatus est, ut nullo iuvamine inferioris nature indigeat, quia nec tegumentis nec ornamentis nec esculentis, sed omnia sibi necessaria habuit naturaliter ordinata ut aerem, sic quod soli Deo serviens omnibus naturis corporeis naturaliter dominetur (TDSI, C. 5, p. 501).

${ }^{12}$ Et illud philosophicum docetur in historia Gen. II (TDSI, C. 5, p. 501).

${ }^{13}$ Tercio principaliter instatur per hoc quod non clare docetur quod omnia temporalia forent omnibus et singulis innocentibus communia, quod tamen supponitur in sentenciis supradictis (TDSI, C. 6, p. 505).

${ }^{14}$ Ista materia requirit noticiam dominii, proprietatis et communitatis (TDSI, C. 6, p. 505).

${ }^{15}$ Quibus hic suppositis patet quod in statu innocencie forent cuncta cunctis communia, ut idem Deus foret omnibus creaturis, et cum omnis innocens naturaliter dominaretur omnibus ibi inferioribus in natura, patet quod omnes homines communicarent in omnibus que haberent (TDSI, C. 6, p. 505).

${ }^{16}$ Patet respicienti verba concessionis divine Gen. I, 26: Faciamus, inquit trinitas, hominem ad imaginem et similitudinem nostram, ut presit piscibus maris et volatilibus celi el bestiis terre omnique reptili quod movetur super terram (TDSI, C. 6, p. 505).

${ }^{17}$ Et pari evidencia dedisset cuilibet innocenti naturale dominium, cum a quolibet tali exigeret obsequium et per consequens ordinaret sibi medium necessarium ad ministerium exequendum. Et patet quod quilibet innocens haberet auctoritatem utendi quocunque sibi necessario ad hunc finem. Item, quilibet innocens uteretur quolibet suo inferiori in natura et non illicite quod non foret suum, ergo omnis innocens haberet dominium omnis huiusmodi (TDSI, C. 6, p. 506).

${ }^{18}$ Consideret ergo philosophus quod appropriacio civilis solum inducitur ad refrenandum viciosos, qui aliter abuterentur temporalibus, si semper ad votum suppeterent; et patet quod repugnat statui innocencie civilis proprietas, nec alique leges vel raciones huic dissenciunt sed concorditer contestantur, cum superflueret talem civilitatem inducere, ubi illa subducta cuncta sufficerent (TDSI, C. 6, p. 506).
} 
la modalidad del servicio mutuo. ${ }^{19} \mathrm{Y}$ aquí Wyclif remite a Agustín, sin citarlo expresamente, cuando enuncia lo que va a ser uno de los principales ejes de su propuesta de reforma: todas las cosas son del justo y, por consiguiente, todo el que es justo - y solo él - es verdaderamente rico. ${ }^{20}$ Para aclarar este razonamiento Wyclif se vale de una serie de ejemplos que ilustrarían el hecho de que los miembros y accidentes de cualquier persona les son propios (en cuanto a la posesión relativa) y comunes (en cuanto al uso). ${ }^{21}$

Wyclif dedica el último capítulo de su tratado al tema del dominio de los ángeles, donde resuena claramente el Pseudo Dionisio Areopagita, en especial sus jerarquías celestiales. Su dominio se ejerce sobre todos los seres corpóreos - incluidos, en consecuencia, los seres humanos - y revela la excelencia de su naturaleza y de su servicio a Dios. ${ }^{22}$ Acá nuestro autor desciende también a las jerarquías eclesiásticas, y recuerda que Cristo preservó a los inocentes del dominio temporal, así como les prohibió su ejercicio a los sacerdotes. ${ }^{23}$ Vemos aparecer, nuevamente, su preocupación por la situación de la Iglesia en la tierra, y la que él considera urgente necesidad de reformarla. Tanto el estado de inocencia como el de bienaventuranza, junto con la referencia al dominio de los ángeles, sirven así como un laboratorio para estudiar a la humanidad postlapsaria.

Detenemos aquí nuestro punteo sobre el tratado porque consideramos que ya está presentado lo que pretendemos abordar en este artículo, y nos vamos a valer a continuación

\footnotetext{
${ }^{19}$ Ex quibus plane patet quod innocens utitur qualibet parte mundi, nam quelibet pars mundi benefacit mihi, de quanto causaliter terminat meam noticiam et complacenciam ordinatam; quia cum actus huiusmodi sit mihi utilis, ex quo inde placeo Deo, patet quod omnis creatura causans in me illum actum bonum adeo servit mihi ipsi et per idem ego servio mihi ipsi tam secundum corpus quam animam (TDSI, C. 6, p. 507).

${ }^{20} \mathrm{Et}$ patet quod iustus laudans Deum meritorie in istis transitoriis habet de eis ut sic utilem usum fructus; ex quo patet quod iusti sunt omnia, et per consequens omnis iustus et solus huiusmodi est realiter vere dives (TDSI, C. 6, p. 508).

${ }^{21}$ Ex istis colligitur solucio ad argumentum factum superius, concedendo quod membra et accidencia cuiuslibet persone humane sunt sibi propria et tamen communia; propria quoad habicionem relativam et communia quoad usum (TDSI, C. 6, p. 508).

${ }^{22}$ Sed dimissa ista contencione verbali superest tractando de dominio status innocencie dicere aliquod de dominio angelorum. Constat quidem quod angeli confirmati dominantur super universitate nature corporee, quia habent super illa excellenciam naturalem. Et correspondenter ad illam excellenciam habent dominium; unde sicut angeli de nono ordine non solum ardent caritate, cum omnibus illis novem ordinibus caritas sit communis, sic non solum angeli qui dominaciones dicuntur super suis subditis dominantur sed generaliter omnes angeli illi beati tam super actus proprios quam opera debite dominantur (TDSI, C. 10, p. 522).

${ }^{23}$ De gradibus autem officii horum ministrorum et de particulari suo dominio relinquo superioribus theologis pertractandum, unum sciens quod angeli beati sine defectu vel superbia serviunt Deo suo et considerando quantum distat horum angelorum ministerium a ministerio seculari, nos terreni et specialiter clerici seculare dominium odiremus; nihil enim prodest nobis nisi ut loquar ironice ad luciferinam superbiam acuendum; retardat enim clericos ab officio sacerdotis, cum gravat eos ultra alimenta et tegumenta sufficiencia; et hec racio naturalis quare Christus innocens preservavit se a tali dominio, et clero suo prohibuit taliter dominari (TDSI, C. 10, p. 523).
} 
de algunas interpretaciones que autores actuales han hecho respecto a la relación entre pecado original y dominio en el pensamiento de Wyclif.

En el comienzo de su análisis Boreczky ya indica una importante inflexión que produce Wyclif: cambia el enfoque del pecado original - o incluso del pecado en general moviéndolo desde la preocupación por el problema de la procreación y la fornicación hacia el campo del dominio, la privación y la deuda (BORECZKY, 2008, p. 121). Este autor lee los últimos capítulos del tratado de Wyclif sobre el estado de inocencia como una introducción general a sus tratados más extensos sobre el dominio humano. Según los últimos capítulos del TDSI, el dominio humano en el estado de inocencia era un dominio natural: al hablar de dominio se refiere al del alma sobre el cuerpo y todas sus cualidades y miembros, e indica que es natural porque era el dominio sobre la naturaleza inferior. En el estado de inocencia los apetitos del hombre estaban satisfechos, pero él nunca tuvo apetitos inapropiados. Se complacía con los frutos de la tierra, el agua pura para beber y el deleite del sexo. Los sentidos y los miembros del hombre recibían atención en proporción a su fin último. Tener todo esto significaba usarlo y disfrutarlo. Los inocentes tenían la autoridad de usar lo que necesitaran de acuerdo a su fin (BORECZKY, 2008, p. 123).

En este punto Campi sigue la argumentación escolástica que desarrolla Wyclif y presenta la objeción que pone en duda que los bienes temporales sean comunes a todos los inocentes. El conferimiento del dominio natural - un dominio de pares sobre criaturas inferiores - se explica en términos de una dacio, de una concessio, común a todos los inocentes. La concesión del dominio natural instaura una relación de obediencia entre el inocente y Dios, y al mismo tiempo ofrece al hombre los medios necesarios para el cumplimiento de su propio servicio a Dios. Así, la asunción del dominio y el consecuente gobierno sobre lo creado son ordenados a la gloria de Dios. El inocente se sirve de cualquier criatura inferior a él por naturaleza y lo hace de modo totalmente lícito (CAMPI, 2007, p. 108109).

El estado de inocencia presupone la ausencia de relaciones de propiedad: no se da el caso de que un inocente sea propietario de un bien en modo exclusivo. Eso estaría en contra de la naturaleza, porque contrariaría el orden de Dios, que quiere a todos los hombres iguales a su imagen y semejanza, sin excepciones. La civilitas y la proprietas, extrañas al estado de inocencia, caracterizan por el contrario la condición postlapsaria del hombre. Se sugiere así que el dominio civil es un remedio artificial, surgido para paliar el estado de desorden y de 
debilidad en el cual los hombres han caído: la institución del derecho positivo ha comportado la emergencia de la propiedad privada y la instauración de una autoridad coercitiva, necesaria para la organización de la sociedad. Con la caída de Adán el hombre ha perdido de modo irrevocable la "naturalidad" de tal señorío y ha debido instituir el dominio civil (CAMPI, 2007, p. 109).

El núcleo del argumento de Wyclif está claramente identificado: si el uso de los bienes es ordenado al servicio de Dios, resulta evidente que quien se sirve de tales bienes para alabar a Dios goza en modo meritorio. Se cumple la ecuación entre innocens e iustus, a la cual solamente pertenecen todas las cosas en virtud de su iusta natura: todas las cosas son del justo y, por consiguiente, todo el que es justo - y solo él - es verdaderamente rico (CAMPI, 2007, p. 111).

A continuación el filósofo italiano se explaya sobre el concepto de uso. Tomando como ejemplo del bonum utile equum el cuerpo de un inocente, Wyclif puntualiza que eso le pertenece en cuanto a la posesión relativa, pero es un bonum commune a los otros inocentes en lo que concierne a su uso. Se puede decir que un brazo de mi hermano "es mío", sin con eso querer indicar una relación de propiedad: eso "es mío" en cuanto al uso, si me sirve para la gloria de Dios y el servicio de su Iglesia (CAMPI, 2007, p. 112).

Campi resume finalmente algunos aspectos centrales de la interpretación wyclifita del estado de inocencia: el pecado es un acto voluntario y pasible de una justa condena; Dios concede al hombre un ámbito en el cual ejercer la propia libertad; el orden que aloja al pecado es el mejor orden posible del mundo, creado por Dios. Habría sido, entonces, imposible para el hombre permanecer privado del todo del pecado en la eternidad. El interés de Wyclif por el estado de inocencia reside básicamente en su función de unidad de medida de los méritos y deméritos del hombre caído (Campi, 2007, p. 122).

Stephen Lahey, por su parte, sintetiza de la siguiente manera la cuestión que nos preocupa: los humanos fueron creados con un dominio natural, una relación no-propietaria en la cual cada uno podía usar lo que necesitaba de la creación; pero la caída efectivamente finalizó este estado (LAHEY, 1997, p. 11). Y define las diferencias entre el dominio natural y el civil: el dominio natural es inclusivo, holístico y está caracterizado por un cuidado por los otros dirigido hacia el exterior; mientras que el dominio civil es exclusivo, individualista y marcado por el egoísmo y la codicia (LAHEY, 2003, p. 118). 
EI TDSI es, para el filósofo estadounidende, la descripción más completa de la aristocracia armoniosa del dominio natural. Muestra el lugar de la aristocracia en el pensamiento político de Wyclif: es una imagen de la sociedad humana ideal en los términos formulados en respuesta a la caída, que hizo el ideal efectivamente inalcanzable. Pero Lahey también nos indica las contradicciones que están implicadas en este intento de armonizar aristocracia con dominio natural: el dominio natural no puede ser realmente una aristocracia, porque no hay comunes, no hay coerción, y lo más importante, no hay pecado. Si nadie es un aristócrata, es difícil etiquetar la sociedad como una aristocracia (LAHEY, 2003, p. 162). EI TDSI caracteriza la relación de Dios con la creación en términos de dominio, una noción que incorpora los conceptos de propiedad y jurisdicción (LAHEY, 2009, p. 212). Wyclif explora el dominio humano en esta obra, y lo considera un préstamo de Dios, que solo puede ser ejercido por los auténticos señores a través de la gracia dadora de caritas. La justicia humana solo es posible cuando la ley civil está fundada en la ley divina (LAHEY, 1997, p. 6).

En el estado de inocencia la propiedad privada sería desconocida (LAHEY, 2009, p. 211). El dominio con el cual los seres humanos fueron creados no involucraba "lo mío" y "lo tuyo". El señor civil favorecido por la gracia está calificado para disfrutar restaurando el dominio natural, pero debe cargar la responsabilidad del dominio civil en nombre de sus seguidores. A partir de esto Lahey interpreta que Wyclif rechaza el orden feudal y condena la propiedad privada de la Iglesia (LAHEY, 1997, p. 6-7).

En el estado postlapsario desapareció la concordia natural entre los hombres, el poder del hombre sobre los animales y su capacidad para servir a Dios de acuerdo con el orden de su naturaleza. Nos quedamos con voluntades que son propensas a valorar el mundo físico y material por encima de las preocupaciones espirituales, y el resultado inevitable es la propiedad privada y todas las ansiedades y preocupaciones que la acompañan. Ya no entendemos un bien creado dado como un obsequio cedido por Dios, sino que solo podemos verlo en términos de nuestro propio interés. El resultado execrable es el dominio civil, la esclavitud odiosa e interminable a los bienes materiales (LAHEY, 2009, p. 212).

A describir la situación de la humanidad postlapsaria, Wyclif distingue entre la vida contemplativa y la vida activa. La humanidad fue creada para disfrutar de la contemplación de Dios en el dominio natural. La caída introdujo la preocupación sobre la adquisición de alimentos y otros recursos, por lo que la humanidad se vio forzada a abandonar su anterior estilo de vida, más satisfactorio intelectualmente, en favor de una vida activa (LAHEY, 2003, 
p. 163). La redención de Cristo hizo posible la restauración del dominio natural, pero solo para los predestinados, y proporcionó un retorno a la vida contemplativa (LAHEY, 2003, p. 162).

A partir de este análisis, Lahey penetra en los aspectos más políticos del pensamiento de Wyclif, quien considera que los clérigos deben vivir como lo hizo Cristo, y por ello deben abrazar la vida contemplativa. Por su parte, los señores civiles fundados en la gracia, en la vida activa, deben proveer a los clérigos para que puedan recuperar una vida libre de las preocupaciones mundanas. Así, Wyclif considera su propuesta de reforma clerical ampliamente positiva: beneficiará al clero, al rey y extenderá más la justicia en el reino (LAHEY, 2003, p. 163).

Minnis también trabaja sobre el TDSI. Indica que Wyclif intenta regresar al Edén para considerar los orígenes y la naturaleza del señorío: aborda así el dominio de la humanidad sobre los animales, el dominio natural que los hombres compartían antes de la caída y el dominio ejercido por los ángeles (MINNIS, 2012, p. 61).

Antes de la caída el dominio entre los hombres era un dominio natural. En el estado de inocencia las criaturas superiores ejercían el dominio sobre sus inferiores naturales, lo que significa que los hombres tenían el dominio sobre los animales. Los hombres poseían en común entre ellos todo lo que estaba a su disposición. En ese momento no había propiedad privada ni propiedad individual; todo eso se originó después de la caída, con el fin de restringir a las personas viciosas que de otro modo habrían malversado esos bienes que alguna vez fueron comunes. Aquí Wyclif alude a las instituciones de dominio civil; de hecho, algunos suponen que escribió su tratado sobre el estado de inocencia al mismo tiempo en que trabajaba en un tratado mucho más extenso sobre ese tema, el De civili dominio. Allí explica que el dominio civil implica propiedad privada y exclusiva, con toda la organización social necesaria para mantenerlo y defenderlo. Este es un mal necesario requerido por las sombrías condiciones postlapsarias (MINNIS, 2012, p. 71-72).

Para Minnis, lo más sorprendente en Wyclif es su afirmación de que cada parte del mundo es para el uso de los inocentes, y que todas las cosas pertenecen a los justos y solo a ellos (MINNIS, 2012, p. 71). Así es el tipo de vida que los hombres habrían llevado en el Edén: el uso de bienes mantenidos en común, y entre sí, de una manera totalmente decorosa y de apoyo mutuo, y gozando del beneficio que otros derivan de aquellos bienes y de uno mismo. Uno de los aspectos más convincentes de esta doctrina es la suposición de que el estado de inocencia no era exclusivo del Edén. Al comienzo del tratado Wyclif explica que la definición 
de inocencia debe ser comprendida como incluyendo la vida que Cristo llevó y los tiempos en que sus santos - que Minnis identifica con los predestinados - vivieron libres del pecado. Wyclif creía que, gracias al sacrificio de Cristo, los justos eran devueltos a un estado de inocencia (MINNIS, 2012, p. 73).

Minnis aborda entonces, al igual que Lahey, el tema de la aristocracia. Sostiene que Wyclif se sintió atraído por el modelo aristocrático de gobierno, en oposición al monárquico, aunque habría encontrado ciertas ventajas en la realeza de una única mente iluminada. Para Minnis los "aristócratas" no jerárquicos que disfrutaron del dominio natural en el Edén son la principal preocupación de Wyclif en el TDSI (MINNIS, 2012, p. 74).

Para el crítico irlandés, en el tratado en cuestión no hay ninguna sugerencia de que todos en el Edén hubieran sido iguales en inteligencia y capacidad. Wyclif simplemente no investiga ese asunto. Su interés está más bien en la idea de que los humanos eran iguales en su derecho a usar posesiones comunes. Minnis no encuentra ningún indicio en el TDSI - y agrega que en ninguna otra parte del corpus wyclifita - de que en el estado de inocencia algunos "señores" hubieran sido más iguales que otros, que hubiera existido alguna forma de política, aunque solo fuera para asegurar que una persona o personas especialmente dotadas promovieran el bien común y desplegaran sus dones superiores para el beneficio de los demás. ${ }^{24}$ Lo que está bastante claro es que, para el teólogo inglés, en el estado de inocencia no hubo conflictos físicos, ni sistema legal ni disputas; todo eso vino con la caída. Además, las virtudes morales descritas por Aristóteles tampoco tenían lugar en el Edén, ya que en ese momento el hombre no tenía la propensión a hacer el mal que vino después. Por todas estas razones, parece que no había necesidad de un gobernante o una clase gobernante para mantener bajo control al resto de la población, porque toda la población vivía en armonía y en paz. Todos eran conscientes del bien común, y todos lo servían, sin necesitar de la dirección de nadie más, disfrutando el uso mutuo de los bienes comunes, compartiéndolos fácilmente sabiendo que nadie tenía más derecho a ellos que otro (MINNIS, 2012, p. 75-76).

Minnis afirma que, en el TDSI al menos, Wyclif quería mantener la teoría ética y política aristotélica fuera del Edén, en contraste con Tomás de Aquino. Para el pensador inglés la propiedad privada era un gran peligro y, en términos absolutos, una mera ilusión, una consecuencia de la caída que no tuvo un precedente directo en el estado de inocencia. Todos

\footnotetext{
${ }^{24}$ Como sostiene, por ejemplo, Tomás de Aquino.
} 
los miembros de la verdadera Iglesia sostienen su señorío en Cristo; al igual que antes de la caída, la humanidad originalmente posee el dominio por el título de la gracia. Y Wyclif estaba más preocupado por afirmar la igualdad de la que gozaban todos los receptores de la gracia que en buscar diferencias entre ellos. Claramente, esto se debe a su deseo de afirmar la posibilidad de estados de inocencia más allá de los límites históricos y geográficos del Edén (MINNIS, 2012, p. 76).

Dejamos para el final de este recorrido bibliográfico el tema del dominio de los ángeles, que también - como ya indicamos - aparece al final del TDSI. Siguiendo con Minnis, este indica que allí Wyclif aborda una relación jerárquica: la de los ángeles sobre los hombres, que tendría su reflejo - tal vez degradado, agregamos - en el dominio de los hombres sobre los animales. Los Angeli confirmati - Minnis indica que probablemente Wyclif usa ese término para distinguirlos de los ángeles caídos - gobiernan sobre toda la creación corporal; este privilegio se debe a la excelencia de su naturaleza. Aquí, Wyclif habla de los ángeles en general, sin pensar únicamente en los superiores que dominan a los demás. En contraste, el diablo, él mismo un ángel caído -aunque el pensador inglés no explica esto aquí - no es un gobernante, sino un esclavo (servus) del pecado. La gracia o la caridad son necesarias para el señorío; donde faltan, no hay verdadero dominio. Los ángeles buenos sirven a Dios. Este servicio está continuamente libre de pecado y a través de él trabajan incesantemente para cumplir la voluntad de Dios. Wyclif contrasta este servicio con el dominio que caracteriza a su mundo actual, advirtiendo que los clérigos en particular deberían detestar el dominio civil. Nada es más probable que acentúe el orgullo diabólico en nosotros, y, por lo tanto, Cristo preservó a los inocentes de tal dominio y prohibió a sus clérigos ejercerlo (MINNIS, 2012, p. 76-77).

Todas las cosas en el estado de inocencia fueron ordenadas correctamente, con los animales sirviendo al hombre y al hombre sirviendo a Dios; tan pronto como el hombre falló en este servicio, perdió su dominio sobre el resto de la creación. Sin embargo, las leyes que Dios estableció para el estado de inocencia siguen siendo importantes para las criaturas lapsas. Wyclif nos exhorta - afirma Minnis - a estudiar el dominio divino en primer lugar, y luego el dominio tanto antes como después de la caída, recordando en particular que todo dominio relativo a las criaturas tiene su patrón en el dominio divino (MINNIS, 2012, p. 77). Aparecen aquí, añadimos, los tres tipos de dominio que trabaja Wyclif en sus obras.

Boreczky también aporta sobre el tema de los ángeles, indicando que disfrutan del dominio sobre el universo de la naturaleza corporal porque tienen una excelencia natural 
sobre él; su dominio se deriva de su excelencia. Pero su excelencia también es igual a su servicio perfecto a Dios. La brillante luz (del intellect) de los nueve órdenes de ángeles no solo proviene de la caridad, que es común a ello, sino que la luz es un reflejo de su dominio sobre sus propias acciones. El diablo, que está lleno de orgullo (superbia), no domina sus propias acciones internamente, ni gobierna a otras criaturas. La gracia sobre la cual se funda el dominio, necesariamente desiste del dominio mismo. Los que prestan perfecto servicio a Dios disfrutan del dominio. El servicio perfecto es la excelencia en su propio tipo; por lo tanto, los santos e inocentes, que son inmortales en su genus, también lo prestan a Dios y disfrutan del dominio. El servicio a Dios no consiste en alabarlo o glorificarlo, o cantar himnos y practicar rituales, sino en envolverlo en la gloria de la excelencia de su creación. Es por esto que todos los hombres en la tierra, y los sacerdotes seculares en particular, deben evitar el dominio civil (BORECZKY, 2008, p. 125).

En su análisis del pensamiento de Wyclif sobre el dominio, Boreczky afirma que el pecado original se cometió cuando el hombre intentó tomar posesión del mundo terrenal para sí mismo; cuando se apropió de la tierra. Los inocentes, los ángeles o los santos también pecaron, pero Dios les dio poder para restaurar la justicia a través de sus pecados. Los tratados de Wyclif sobre el dominio humano examinan cómo se puede utilizar esta oportunidad, pero el filófoco húngaro considera que el problema del sexo y el trabajo sigue sin resolverse (BORECZKY, 2008, p. 126).

\section{Comentarios finales}

Nuestro interés principal - del cual es tributario el presente artículo - es estudiar cómo afecta la idea cristiana del pecado original a la concepción del dominio del hombre sobre el hombre y qué proyecciones filosófico políticas relevantes de esta relación se pueden identificar en el pensamiento de John Wyclif. A través del TDSI y de otras obras, nuestro autor reconocería tres tipos de dominio, que van desde la inocencia de los seres humanos hasta la salvación de los predestinados, pasando por el de su vida postlapsaria. El dominio natural del Adán inocente y el dominio evangélico de la reconstitución de la inocencia por medio de la encarnación de Cristo son considerados como legítimos por Wyclif. El nivel histórico - el dominium civile - solo puede volverse justo si obtiene la gracia de Dios. En relación a los bienes temporales, la Iglesia solo podría tenerlos en la modalidad de la comunidad de bienes. Los eclesiásticos deberían seguir el modelo de Cristo y sus apóstoles, quienes - como el hombre 
en el estado de inocencia - hicieron uso de bienes tenidos en común. De ahí la reforma radical que propone nuestro autor, con eje en el apartamiento total del clero de lo temporal y su sujeción a las autoridades laicas.

Sostenemos que Wyclif es un claro exponente bajomedieval de la fusión entre teoría y praxis, entre el filósofo y la figura política. La investigación sobre el estudio que lleva a cabo el pensador inglés sobre la relación entre el pecado original y el dominio político nos permitirá acercarnos tanto a un desarrollo coherente y profundo de una teología política innovadora como a los posibles efectos de la misma en la práctica de su propia época y de momentos históricos posteriores.

\section{REFERENCIAS BIBLIOGRÁFICAS}

BIBLIOGRAFIA PRIMÁRIA

WYCLIF, J. Tractatus de statu innocencie. In: LOSERTH, J. and MATHEW, F.D. (Eds.), Tractatus de mandatis divinis. London: The Wyclif Society, 1922, p. 475-524.

BIBLIOGRAFIA SECUNDÁRIA ${ }^{25}$

BORECZKY, Elemér. John Wyclif's Discourse on Dominion in Community. Leiden-Boston: Brill, 2008.

BRIGUGLIA, Gianluca. Stato d'innocenza. Adamo, Eva e la filosofia politica medievale. Roma: Carocci editore, 2017.

BURT, Robert A. In the Whirlwind: God and Humanity in Conflict. Cambridge- London: Harvard University Press, 2012.

CAMPI, Luigi. Iusti sunt omnia: Note a margine del De statu innocencie di John Wyclif. Dianoia, n. 12, 2007, p. 89-123.

LAHEY, Stephen E. Wyclif on Rights. Journal of the History of Ideas, vol. 58, n. 1, 1997, p. 1-20. . Philosophy and Politics en the Thought de John Wyclif. Cambridge-New York: Cambridge University Press, 2003.

LAHEY, Stephen E. John Wyclif. Oxford-New York: Oxford University Press, 2009.

MINNIS, Alastair. Wyclif's Eden: Sex, Death and Dominion. In: BOSE, M. and HORNBECK, P. (Eds.). Wycliffite Controversies: Proceedings of the 2008 Lollard Conference at Oriel College. Oxford, Medieval Church Studies, vol. 23, Turnhout: Brepols, p. 59-78, 2012.

. From Eden to Eternity: Creations of Paradise in the Later Middle Ages. Philadelphia: University of Pennsylvania, 2016.

PAGELS, Elaine. Adán, Eva y la serpiente. Sexo y política en la antigua cristiandad. Barcelona: Crítica, 1998.

${ }^{25}$ Solo se consignará la bibliografia expresamente citada. 